\title{
PEGAMENTO DA ENXERTIA EM DIFERENTES COMBINAÇÕES DE VARIEDADES E ESPÉCIES UTILIZADAS COMO COPA E COMO PORTA-ENXERTOS DE MARACUJAZEIRO ${ }^{1}$
}

\author{
GIVANILDO RONCATTO ${ }^{2}$, GISELLE MARIANO LESSA DE ASSIS ${ }^{3}$, \\ TADÁRIO KAMEL DE OLIVEIRA ${ }^{3}$, LAURO SARAIVA LESSA ${ }^{4}$
}

RESUMO - O Brasil é o maior produtor de maracujá. Mas, apesar da posição de destaque, a vida útil do maracujazeiro vem sendo reduzida, principalmente, devido aos danos causados por doenças do sistema radicular. A enxertia com espécies nativas e resistentes a doenças apresenta-se como alternativa de produção. Com isso, objetivou-se avaliar o pegamento da enxertia nas combinações de variedades-copa e espécies de porta-enxertos de maracujazeiro. $\mathrm{O}$ trabalho foi desenvolvido em viveiro telado (50\% de sombreamento), na Embrapa Acre, em Rio Branco-AC, entre setembro e dezembro de 2007. A variedade-copa utilizada para todos os tratamentos foi o maracujazeiro-amarelo 'FB 100'e 'FB 200' do viveiro Flora Brasil (Araguari-MG) e outras 5 variedades regionais (UFAC-Universidade Federal do Acre, Rio Branco-AC), e os porta-enxertos foram Passiflora edulis Sims (maracujazeiro-amarelo) (acesso Cuiabá-MT), P. alata, P. edulis (maracujazeiroroxo) e $P$. quadrangularis (acesso Guiratinga-MT), P. serrato-digitata (acesso IAC-Campinas-SP). As sementes foram previamente embebidas em água destilada por cerca de $24 \mathrm{~h}$ e posteriormente semeadas em tubetes plásticos $(25 \times 5 \mathrm{~cm})$ com substrato Plantmax ${ }^{\circledR}$. O método de enxertia utilizado foi o de fenda cheia no topo hipocotiledonar, tendo os porta-enxertos as seguintes características: três folhas verdadeiras e altura de plântula variável (6 a 8cm), 30 a 90 dias após a semeadura. Decapitaram-se as plântulas na altura dos cotilédones com lâmina de aço, as quais foram mergulhadas em água sanitária a 70\%, a cada enxertia realizada. Os enxertos foram obtidos de plântula inteira, com cerca de $10 \mathrm{~cm}$ de comprimento, fazendo-se a limpeza das folhas. As combinações de melhor desempenho em relação ao pegamento da enxertia foram UFAC 07 sobre $P$. edulis (maracujazeiro-roxo) e P. alata, UFAC 38 sobre P. edulis (maracujazeiro-amarelo), $P$. edulis (maracujazeiro-roxo) e P. alata, UFAC 64 sobre $P$. serrato-digitata, com $100 \%$ de pegamento da enxertia, enquanto a combinação FB 100 sobre $P$. alata teve o pior desempenho, com baixo índice de pegamento, não alcançando $30 \%$.

Termos para Indexação: Enxertia, passifloras nativas, propagação de plantas.

\section{GRAFTING SUCESS IN DIFFERENT COMBINATIONS OF SPECIES AND VARIETIES USED AS SCION AND THE ROOTSTOCK OF PASSION FRUIT PLANT}

\begin{abstract}
Brazil is the largest producer of passion fruit. But, in spite of its prominent position, life of passion fruit plant has been reduced mainly due to damage caused by root diseases. As grafting with native species is resistant to diseases, presenting an alternative of production, this research aimed to evaluate the success of grafting in the combinations of scion varieties and species of rootstocks of passion fruit plant. The study was conducted in screenhouse (50\% shaded) at Acre Embrapa, Rio Branco, between September and December in 2007. The scion variety used for all treatments was the yellow passion fruit 'FB 100' and 'FB 200' from Flora Brazil (Araguari, MG) nursery and 5 other regional varieties (UFAC, Universidade Federal do Acre, Rio Branco-AC) and the rootstocks were Passiflora edulis (yellow passion fruit) (Cuiabá-MT), $P$. alata, $P$. edulis (purple passion fruit) and $P$. quadrangularis (Guiratinga-MT), P. serrato-digitata (IACCampinas/SP). The seeds were previously soaked in distilled water for about $24 \mathrm{~h}$ and then sown in plastic tubes $(25 \times 5 \mathrm{~cm})$ with Plantmax ${ }^{@}$. The cleft at the top hypocotyledonary was the grafting method used, and the rootstocks had the following characteristics: three true leaves and seedling height variable $(6$ to $8 \mathrm{~cm})$, 30 to 90 days after sowing. Seedlings were decapitated up to cotyledons with steel blade, which has been dipped in bleach to $70 \%$, at each grafting performed. The grafts were obtained from whole seedlings, about $10 \mathrm{~cm}$ long, and the toilet of the leaves was made. The combination of better performance in relation to the living grafts were UFAC 07 on $P$. edulis (purple passion fruit) and P. alata, UFAC 38 on P. edulis (yellow passion fruit), $P$. edulis (purple passion fruit) and $P$. alata, UFAC 64 on $P$. serrato-digitata, with $100 \%$ of grafting success, while the combination of FB 100 on $P$. alata had the worst performance, with low rate of success, not reaching $30 \%$.
\end{abstract}

Index terms: Grafting, Passifloraceae, propagation of plants.

\footnotetext{
${ }^{1}$ (Trabalho 064-10). Recebido em: 04-03-2010. Aceito para publicação em: 24-05-2011.

${ }_{2}^{2}$ Pesquisador A - Embrapa Mato Grosso. Escritório Itaúbas - Av. das Itaúbas, 3257 - Setor comercial, Cep 78550-194 Sinop-MT. E-mail: givanildo.roncatto@embrapa.br

${ }^{3}$ Pesquisador A - Embrapa Acre. Rodovia BR 364 km 14, Cx 321, Zona Rural, Cep 69901180 Rio Branco-AC. Emails:giselle@cpafac.embrapa.br, tadario@cpafac.embrapa.br

${ }^{4}$ Analista A - Embrapa Acre. Rodovia BR 364 km 14, Cx 321, Zona Rural, Cep 69901180 Rio Branco-AC. E-mail: laurolessa@cpafac.embrapa.br
} 


\section{INTRODUÇÃO}

O maracujazeiro é uma cultura típica de países tropicais, sendo o Brasil responsável por cerca de $90 \%$ da produção mundial (SILVA et al., 2005). O Brasil é o maior produtor de maracujá, produzindo 684 mil toneladas de frutos em 2007 (IBGE 2010). Os maiores produtores são os Estados da Bahia, São Paulo, Sergipe, Espírito Santo, Pará, Ceará e Minas Gerais, que representam $80 \%$ da produção nacional, sendo que o Estado da Bahia representa $40 \%$ da produção, com 275 mil toneladas de frutos. A produtividade média nacional é baixa, com cerca de 13 t/ha/ano. O Estado do Acre apresenta uma das mais baixas produtividades e produções de maracujá, representando apenas $0,1 \%$ da produção brasileira, com produtividade de $6 \mathrm{t} / \mathrm{ha} / \mathrm{ano}$, tendo de importar de outras regiões produtoras (IBGE, 2010).

A baixa produção e produtividade do maracujazeiro no Estado, bem como a menor qualidade de frutos são causadas por muitos fatores, principalmente pela falta de tecnologias adaptadas para a região. E, no caso do maracujazeiro-amarelo, o método mais utilizado é o da propagação por sementes, e apresenta várias limitações, dependendo da variedade utilizada, como baixa produtividade, frutos pequenos, pomares desuniformes, com plantas produtivas e improdutivas, suscetibilidade a pragas e doenças.

Novas tecnologias mais apropriadas devem ser geradas, e métodos alternativos devem ser oferecidos aos produtores, a fim de explorar o potencial da cultura em sua plenitude. Um deles é a enxertia, que proporciona a possibilidade de propagar plantas de espécies nativas resistentes ou tolerantes à seca, a pragas, a nematoides e a doenças como a fusariose (Fusarium oxysporum Schlecht. f. passiflorae Purss.), evitando a morte prematura de plantas. Esta última consiste na murcha repentina da planta pelo apodrecimento do colo, e consequentemente o interrompimento da passagem da seiva da planta, ocasionando baixa longevidade da cultura e abandono de áreas com grande quantidade de inóculo.

Sendo assim, a preservação dessas características de resistência permite que se utilizem espécies resistentes ou tolerantes como porta-enxerto do maracujá-amarelo, formando lavouras sadias (DELANÖE, 1991; JUNQUEIRA et al., 2006).

Outro aspecto importante é a clonagem de plantas, visto que o método convencional, que é o propagado por sementes, transmite baixa percentagem das características desejáveis agronomicamente dos seus progenitores, seja ela produtividade, qualidade dos frutos, resistência a pragas e doenças, devido à segregação de caracteres inerente ao método.
Com isso, a enxertia permite a transmissão fiel das características oferecidas pelas matrizes, possibilitando a formação de pomares homogêneos, produtivos e precoces (LIMA et al., 1994).

De forma geral, os resultados obtidos para pegamento da enxertia encontrados na literatura são contraditórios (CORRÊA, 1978; OLIVEIRA et al.,1983; PACE, 1983; SEIXAS et al., 1987; BACCARIN, 1988; MENEZES, 1990; STAVELEY; WOLSTENHOLME, 1990; STENZEL; CARVALHO, 1992; MENEZES et al., 1994; KIMURA, 1994; LIMA et al., 1997; LIMA et al., 1999; LIMA, 1999; CHAVES et al., 2004). Vale ressaltar a variação de métodos, porta-enxerto e mesmo enxertos encontrados nessa literatura, precisando-se de novos estudos. Também se verifica uma grande variação no pegamento relatado na literatura, mesmo quando utilizados o mesmo método de enxertia e a mesma combinação enxerto/porta-enxerto. Assim, o trabalho teve como objetivo avaliar o pegamento da enxertia de combinações de variedades-copa e espécies portaenxertos de maracujazeiro.

\section{MATERIAL E MÉTODOS}

O trabalho foi desenvolvido no viveiro experimental da Embrapa Acre, em Rio Branco-AC, no período compreendido de setembro a dezembro de 2007. O município está a $10^{\circ} 1^{\prime} \mathrm{S}$ e $67^{\circ} 42^{\prime} \mathrm{W}$, à altitude de $160 \mathrm{~m}$. O clima é do tipo AWI (quente e úmido), conforme a classificação de Köeppen, com temperatura máxima de $30,92^{\circ} \mathrm{C}$, temperatura mínima de $20,84^{\circ} \mathrm{C}$, precipitação anual de $1.648,94$ $\mathrm{mm}$ e umidade relativa de $83 \%$ (AGRITEMPO, 2008).

O viveiro experimental possui estrutura coberta por telado do tipo sombrite, de cor preta, proporcionando $50 \%$ de sombreamento às mudas de maracujazeiro. O sistema de irrigação por microaspersão proporcionou regas diárias na sobrecopa, considerando que as bandejas de tubetes com as mudas enxertadas ficaram suspensas a aproximadamente $0,5 \mathrm{~m}$ do solo, dispostas nas bancadas de alvenaria. Desta forma, a aeração levou a uma poda das raízes que ultrapassaram o recipiente. Do contrário, as raízes tocariam o chão, podendo ultrapassar o recipiente e prejudicando o desenvolvimento das mudas.

Foram realizadas duas semeaduras para a obtenção dos porta-enxertos. Na primeira (0309-2007), utilizaram-se 100 sementes de cada porta-enxerto sem qualquer tratamento prévio. $\mathrm{E}$ na segunda (04-10-2007), foram utilizadas 120 sementes de cada porta-enxerto, previamente 
embebidas em água destilada por cerca de doze horas $\mathrm{e}$, posteriormente, semeadas em tubetes de polietileno com substrato comercial Plantmax para hortaliças. Da mesma forma, foram produzidos os "seedlings" de maracujazeiro-amarelo para fornecimento dos garfos, semeando-se a cada semana 100 sementes em tubetes, durante sete semanas.

Quando os porta-enxertos e os enxertos atingiram a fase de enxertia (outubro/novembro de 2007), cerca de 6 a $8 \mathrm{~cm}$ de altura e três folhas definitivas, o que ocorreu com cerca de 30 dias após a semeadura para as espécies mais precoces ou vigorosas, e 90 para as de crescimento mais lento, realizou-se a enxertia. O método de enxertia utilizado foi o de fenda cheia no topo hipocotiledonar.

As variedades-copa utilizadas para todos os tratamentos foram o maracujazeiro-amarelo 'FB 100' e 'FB 200' (Flora Brasil 100 e 200) do viveiro Flora Brasil (Araguari-MG). Estas seleções foram obtidas através da mistura de vários genótipos desenvolvidos na região de Araguari - MG, com objetivo de obter frutos para a indústria; entretanto, usa-se para o consumo in natura, pois tem como características frutos com maior uniformidade de tamanho, formato e cor (peso médio de $240 \mathrm{~g}$ ), casca mais grossa, proporcionando maior resistência durante o transporte, rendimento de polpa em torno de $36 \%$, $14,0^{\circ}$ Brix, com potencial produtivo de $50 \mathrm{t} / \mathrm{ha} / \mathrm{ano}$.

As outras 5 variedades regionais (UFACUniversidade Federal do Acre, Rio Branco-AC), também utilizadas como copa, ainda estão sendo avaliadas quanto às suas características produtivas e de qualidade de frutos. Os porta-enxertos foram Passiflora edulis (maracujazeiro-amarelo) (acesso Cuiabá-MT), P. alata, P. edulis (maracujazeiro-roxo) e $P$. quadrangularis (acesso Guiratinga-MT), $P$. serrato-digitata (acesso IAC-Campinas-SP).

O porta-enxerto foi decepado nos cotilédones, abrindo-se uma fenda longitudinal $(1,0 \mathrm{~cm})$. Após feita a retirada do garfo também decepado abaixo dos cotilédones, de forma que fosse explorado até a região do colo, fez-se uma cunha em bisel duplo, expondo os tecidos do câmbio com uma lâmina de platina. Em seguida, foi feita a união enxerto e porta-enxerto, com cuidado, para coincidir os tecidos cambiais e utilizando-se fita adesiva (crepe) para envolver a região da enxertia, protegendo-a, evitando seu ressecamento, assim como o excesso de umidade e funcionando também como tutor da muda.

Imediatamente após a realização da enxertia propriamente dita, a muda já enxertada e acondicionada em bandejas de tubetes foi tutorada por uma estaca de madeira $(25 \mathrm{~cm})$ e protegida por um saco plástico transparente $(4 \times 23 \mathrm{~cm})$ para formar uma câmara úmida. Após 20 dias, foi retirado o saco plástico transparente. O substrato utilizado foi o composto de uma mistura de terra, esterco de curral curtido e vermiculita $(3: 1: 1, \mathrm{v}: \mathrm{v})$, sendo acondicionado nos tubetes de polietileno pretos, com dimensões de $25 \times 5 \mathrm{~cm}$ ou $288 \mathrm{~cm}^{3}$.

O delineamento experimental foi o de blocos ao caso, com 6 repetições. Os tratamentos foram 35 combinações copa/porta-enxerto (combinação de 5 portas-enxertos $x 7$ copas), numa análise fatorial simples $(5 \times 7)$ para estimar o efeito de cada portaenxerto, de cada copa e da provável interação copa $x$ porta-enxerto no pegamento da enxertia. Cada parcela foi constituída por 8 plantas, sem bordadura. Nesta fase, foi avaliado o pegamento de mudas representado pela percentagem de mudas enxertadas, que tiveram êxito aos 30 dias após a enxertia, em cada indivíduo. Os dados foram submetidos à análise de variância, e as médias, ao teste de Scott \& Knott, a $5 \%$ de probabilidade. Testes de comparação de médias foram feitos para os porta-enxertos e para as copas, individualmente, e em tabela de dupla entrada no caso da interação significativa.

\section{RESULTADOS E DISCUSSÃO}

Os resultados do pegamento da enxertia foram excelentes em determinadas combinações de copa/porta-enxerto, alcançando $100 \%$ de pegamento, como é o caso da combinação UFAC 07 sobre $P$. edulis (maracujazeiro-roxo) e P. alata, UFAC 38 sobre $P$. edulis (maracujazeiro-amarelo), $P$. edulis (maracujazeiro-roxo) e $P$. alata, UFAC 64 sobre $P$. serrato-digitata (Tabela 1). Salienta-se que, na maioria das espécies e variedades utilizadas, a percentagem de pegamento superou os $80 \%$, porém em outras combinações o pegamento ficou aquém do esperado, como é o caso do $P$. alata sob FB 100 com menos de $30 \%$ de pegamento $(25,16 \%$ - o menor valor comparado às demais).

$\mathrm{Na}$ Tabela 1, observa-se ainda que as combinações de melhor desempenho em relação ao pegamento da enxertia foram aquelas que utilizaram as variedades-copa sobre $P$. edulis (maracujazeiroamarelo), P. edulis (maracujazeiro-roxo) e P. serratodigitata, P. alata (exceto FB 100) e P. quadrangularis sobre UFAC 38 utilizadas como porta-enxerto sobre aquelas variedades-copa.

As variedades-copa e as espécies de portaenxertos em combinações que também obtiveram bom desempenho foram FB 100 sobre P. serratodigitata e $P$. quadrangularis, FB 200 sobre $P$. serrato-digitata, $P$. alata e $P$. quadrangularis, UFAC 70 sobre $P$. serrato-digitata e $P$. alata, UFAC 
38 sobre $P$. serrato-digitata e $P$. quadrangularis e UFAC 64 sobre P. alata. Estas obtiveram percentagens de pegamento da enxertia superiores a $77 \%$, demonstrando que houve relação perfeita entre as variedades-copa e as espécies porta-enxertos envolvidos, resultando numa excelente performance, porém inferiores na significância estatística àquelas variedade-copas e espécies mencionadas num primeiro momento.

Observa-se, ainda, que as combinações FB 100 sobre $P$. alata, bem como UFAC 07, 70; 25 e 64 sobre $P$. quadrangularis, foram diferentes das combinações mencionadas anteriormente, posicionando-se no mesmo grupo de significância, demonstrando que foram inferiores na comparação com as demais, posicionando-se abaixo das demais combinações de variedades-copa e de espécies para porta-enxerto de maracujazeiros.

Estes resultados estão de acordo com os obtidos por Nogueira Filho (2003) e Nogueira Filho et al. (2005), que obtiveram resultados semelhantes com as combinações do FB 200 sobre P. edulis (maracujazeiro-amarelo) e P. alata. Também, Menezes (1990) e Menezes et al. (1994) conseguiram excelente pegamento utilizando combinações daqueles porta-enxertos mencionados anteriormente. Já Chaves et al. (2004), Silva et al. (2005) e Junqueira et al. (2006) obtiveram alto desempenho com os referidos porta-enxertos oriundos de estacas. Porém, Lenza et al. (2009) conseguiram resultados de pegamento excelentes utilizando $P$. edulis (maracujazeiro-roxo) e $P$. quadrangularis, o que foi observado também no presente estudo.

Isso pode estar relacionado a uma ótima junção no ponto de enxertia, ocasionada pela uniformidade do material, quanto ao diâmetro e também lignificação dos tecidos dos enxertos e porta-enxertos, ou seja, o diâmetro e a lignificação dos tecidos de ambos os materiais vegetais são semelhantes, permitindo ótima junção e soldadura dos tecidos. Pode-se considerar que a enxertia do tipo hipocotiledonar minimizou as diferenças em relação ao diâmetro do caule e lignificação dos tecidos, existentes em plantas adultas destas espécies e variedades. Isso se deve ao fato de empregarem-se plântulas para execução deste tipo de enxertia.

No estágio de plântula, as características de desuniformidade de diâmetro e lignificação dos tecidos ainda não se manifestaram, favorecendo a junção dos indivíduos e a soldadura dos tecidos na região da enxertia. Além disso, deve-se considerar a característica de caule isoporizado, presente em enxertos de plantas adultas, ainda não manifestada no estádio de plântulas, que pode ter facilitado a união dos tecidos.

Observa-se ainda, na Tabela 1, que a maioria das combinações de variedades-copa e espécies de porta-enxerto obtiveram índices de percentagem de pegamento superiores a $80 \%$, representados pela percentagem de $83,5 \%$ da combinação UFAC 38 sobre $P$. quadrangularis, que está posicionada no limite inferior do grupo de combinações, com pegamento superior às demais $(83,5 \%$ de pegamento da enxertia), demonstrando que, no geral, o pegamento das variedades-copa com as espécies de porta-enxerto foi muito bom.

Entretanto, a combinação FB 100 sobre $P$. alata teve o pior desempenho, com baixo índice de pegamento, não alcançando $30 \%$. Provavelmente, a lignificação de tecidos das espécies de porta-enxerto e das variedades-copa utilizadas nesta combinação não é uniforme, muito embora se tenha o cuidado de eleger os diâmetros semelhantes de ambas as partes, na ocasião da execução da enxertia, com a característica de caule isoporizado ainda não manifestada, sendo esta característica de lignificação de tecido vegetal decisiva no resultado. Isso mostra que não são todas as espécies e variedades que têm afinidade quanto à técnica de enxertia. 
TABELA 1 - Percentagem de pegamento da enxertia, para as combinações de variedades-copa e espécies de porta-enxerto de maracujazeiro, aos 30 dias após a enxertia, em viveiro experimental da Embrapa Acre. Rio Branco-AC.

\begin{tabular}{|c|c|c|c|c|c|}
\hline \multirow[b]{2}{*}{ Copas } & \multicolumn{5}{|c|}{ PEGAMENTO DA ENXERTIA (\%) } \\
\hline & $\begin{array}{c}\text { P. edulis } \\
\text { (maracujá- amarelo) }\end{array}$ & $\begin{array}{c}P . \text { edulis } \\
\text { (maracujá- roxo) }\end{array}$ & P. serrato-digitata & P. alata & P. quadrangularis \\
\hline FB100 & $87,83 \mathrm{Aa}$ & $98,00 \mathrm{Aa}$ & $77,50 \mathrm{Bb}$ & $25,16 \mathrm{Cb}$ & $69,00 \mathrm{Bc}$ \\
\hline FB200 & $98,00 \mathrm{Aa}$ & $94,00 \mathrm{Aa}$ & $83,66 \mathrm{Ba}$ & $77,33 \mathrm{Bb}$ & $62,83 \mathrm{Bc}$ \\
\hline G07 & $96,00 \mathrm{Aa}$ & $100,00 \mathrm{Aa}$ & $92,00 \mathrm{Aa}$ & $100,00 \mathrm{Aa}$ & $44,00 \mathrm{Cb}$ \\
\hline G70 & $98,00 \mathrm{Aa}$ & $96,00 \mathrm{Aa}$ & $87,83 \mathrm{Ba}$ & $77,16 \mathrm{Bb}$ & $52,33 \mathrm{Cc}$ \\
\hline G38 & $100,00 \mathrm{Aa}$ & $100,00 \mathrm{Aa}$ & $87,66 \mathrm{Bb}$ & $100,00 \mathrm{Aa}$ & $83,50 \mathrm{Ab}$ \\
\hline G25 & $96,00 \mathrm{Aa}$ & $85,66 \mathrm{Aa}$ & $93,83 \mathrm{Aa}$ & $89,83 \mathrm{Aa}$ & $54,50 \mathrm{Cb}$ \\
\hline G64 & $98,00 \mathrm{Aa}$ & $89,66 \mathrm{Ab}$ & $100,00 \mathrm{Aa}$ & $81,50 \mathrm{Bb}$ & $41,83 \mathrm{Cc}$ \\
\hline MÉDIA & 96,26 & 94,76 & 88,96 & 78,71 & 58,28 \\
\hline CV $(\%)$ & & & 12,95 & & \\
\hline
\end{tabular}

Médias seguidas de letra iguais, maiúscula na coluna e minúscula na linha, não diferem entre si, pelo teste de Scott \& Knott, a 5\% de probabilidade.

\section{CONCLUSÕES}

As combinações de melhor pegamento da enxertia foram UFAC 07 sobre $P$. edulis (maracujazeiro-roxo) e P. alata, UFAC 38 sobre P. edulis (maracujazeiro-amarelo), P. edulis (maracujazeiro-roxo) e P. alata, UFAC 64 sobre P. serrato-digitata, com $100 \%$ de pegamento da enxertia.

A combinação FB 100 sobre $P$. alata teve o pior desempenho, com baixo índice de pegamento, não alcançando $30 \%$. A maioria delas ficou acima de $80 \%$ de pegamento.

\section{REFERÊNCIAS}

AGRITEMPO. Sistema de monitoramento agrometeorológico. Dados meteorológicos: Acre. Disponível em: <http://www.agritempo.gov.br/ agroclima/sumario? $\mathrm{uf}=\mathrm{AC}>$. Acesso em: 23 set. 2008.

BACCARIN, M.N.R.A. Cultura de tecidos e enxertia em Passifíora spp. 1988 101f. Dissertação (Mestrado em Agronomia, Área de Fitotecnia) Escola Superior de Agricultura Luiz de Queiroz, Universidade de São Paulo, Piracicaba, 1988.
CHAVES, R. da C.; JUNQUEIRA, N.T.V.; MANICA, I.; PEIXOTO, J.R.; PEREIRA, A.V.; FIALHO, J.F. Enxertia de maracujazeiro-azedo em estacas herbáceas enraizadas de espécies de passifloras nativas. Revista Brasileira de Fruticultura, Jaboticabal, v.26, n.1, p.120-123, 2004.

CORRÊA, L.S. Contribuição ao estudo da enxertia por garfagem em maracujá (Passiflora edulis Sims f. flavicarpa Deg.) durante a fase de viveiro. 1978. 43 f. Dissertação (Mestrado em Agronomia) - Faculdade de Ciências Agrárias e Veterinárias, Universidade Estadual Paulista, Jaboticabal, 1978.

DELANOË, O. Etude de la résistance de passiflores de Guyane française vis-à-vis de Fusarium pathogènes de la culture dês fruits de la Passion (Passiflora edulis Sims f. flavicarpa). Fruits, Paris, v. 46, n. 5, p. 593-600, 1991.

IBGE - Instituto Brasileiro de Geografia e Estatística. Produção Agrícola Municipal. Maracujá. Brasília: Ministério do Planejamento, Orçamento e Gestão, 2010. Disponível em: $<$ http://www.sidra.ibge.gov. $\mathrm{br} / \mathrm{bda} /$ tabela/protabl.asp? $\mathrm{z}=\mathrm{t} \& \mathrm{o}=10 \& \mathrm{i}=\mathrm{P}>$. Acesso em: 19 jan. 2010.

JUNQUEIRA, N.T.V.; LAGE, D.A. da C.; BRAGA, M.F.; PEIXOTO, J.R.; BORGES, T.A.; ANDRADE, S.R.M. de. Reação a doenças e produtividade de um clone de maracujazeiro-azedo propagado por estaquia e enxertia em estacas herbáceas de Passiflora silvestre. Revista Brasileira de Fruticultura, Jaboticabal, v.28, n.1, p. 97-100, 2006. 
KIMURA, A. Estudo da enxertia hipocotiledonar de plântulas em Passiflora edulis Sims f. flavicarpa Deg. 1994. 56 f. Monografia (Trabalho de graduação em Agronomia) - Faculdade de Ciências Agrárias e Veterinárias, Universidade Estadual Paulista, Jaboticabal, 1994.

LENZA, J.B.; VALENTE, J.P.; RONCATTO, G.; CHIG, L.A. Índice de pegamento e precocidade de mudas da variedade FB200 enxertada em diferentes espécies silvestres e comerciais de maracujazeiro. Revista Brasileira de Fruticultura, Jaboticabal, v.31, n.3, p.831-836, 2009.

LIMA, A.A. (Coord.). O cultivo do maracujá. Cruz das Almas: Embrapa Mandioca e Fruticultura, 1999. 130p. (Circular Técnica, 35).

LIMA, A.A.; BORGES, A.L.; SANTOS FILHO, H.P.; SANTOS, L.B.; FANCELLI, M.; SANCHES, N.F. Instruções práticas para o cultivo do maracujazeiro Cruz das Almas: Embrapa Mandioca e Fruticultura, 1994. 49p. (Circular Técnica, 20).

LIMA, A.A.; CALDAS, R.C.; CUNHA, M.A. P.; SANTOS FILHO, H.P. Avaliação de porta - enxertos e tipos de enxertia para o maracujazeiro-amarelo. Revista Brasileira de Fruticultura, Jaboticabal, v. 21, n. 3, p. 318-321, 1999.

LIMA, A.A.; SANTOS FILHO, H.P.; CALDAS, R.C. Porta-enxertos e tipos de enxertia para o maracujazeiro-amarelo. Cruz das Almas: Embrapa Mandioca e Fruticultura, 1997. 3p. (Comunicado Técnico, 50)

MENEZES, J.M.T. Seleção de porta-enxertos tolerantes à morte prematura de plantas para $\boldsymbol{P}$. edulis Sims f. fíavicarpa Deg. e comportamento de $P$. nitida H.B.K, na região de Jaboticabal. 1990. 73f. Dissertação (Mestrado em Melhoramento Genético Vegetal) - Faculdade de Ciências Agrárias e Veterinárias, Universidade Estadual Paulista, Jaboticabal, 1990.

MENEZES, J.M.T.; OLIVEIRA, J.C. de; RUGGIERO, C.; BANZATTO, D.A. Avaliação da taxa de pegamento de enxertos de maracujá-amarelo sobre espécies tolerantes à ,morte prematura de plantas“. Científica, Jaboticabal, v. 22, n. 1, p. 95104, 1994.

NOGUEIRA FILHO, G.C. Competição de sete espécies de maracujazeiro propagadas por enxertia hipocotiledonar. 2003. 95f. Tese (Doutorado em
Agronomia, Área de Produção Vegetal) - Faculdade de Ciências Agrárias e Veterinárias, Universidade Estadual Paulista, Jaboticabal, 2003.

NOGUEIRA FILHO, G.C.; RONCATTO, G.; RUGGIEIRO,C.; OLIVEIRA, J.C. de; MALHEIROS, E.B. Propagação vegetativa do maracujazeiroconquista de novas adesões. In: FALEIRO, F.G.; JUNQUEIRA, N.T.V.; BRAGA, M.F. (Ed.). Maracujá: germoplasma e melhoramento genético. Planaltina: Embrapa Cerrados, 2005. p.341-358.

OLIVEIRA, J.C.; RUGGIERO, C.; NAKAMURA, K.; BAPTISTA, M. Comportamento de Passiflora edulis enxertada sobre $P$. giberti N. E. Brow. In: CONGRESSO BRASILEIRO DE FRUTICULTURA, 7., 1983, Florianópolis. Anais... Florianópolis: Sociedade Brasileira de Fruticultura, 1983. p. 989-993.

PACE, C.A.M. Comparação de quatro métodos de enxertia para o 'maracujazeiro-amarelo' Passiflora edulis Sims f. flavicarpa Deg. In: CONGRESSO BRASILEIRO DE FRUTICULTURA, 7., 1983, Florianópolis. Anais... Florianópolis: Sociedade Brasileira de Fruticultura, 1983. p. 983-988.

SEIXAS, L.F.Z.; OLIVEIRA, J.C.; TIHOHOD, D.; RUGGIERO, C. Comportamento de Passiflora macrocarpa como porta-enxerto para Passiflora edulis Sims f. flavicarpa Deg., cultivado em local com histórico de morte prematura de plantas e nematoides do maracujazeiro. In: CONGRESSO BRASILEIRO DE FRUTICULTURA, 9., 1987, Campinas. Anais... Campinas: Sociedade Brasileira de Fruticultura, 1987. p. 597-601.

SILVA, F.M.; CORREA, L. de S.; BOLIANI, A.C.; SANTOS, P.C. dos Enxertia de mesa de Passiflora edulis Sims f. flavicarpa Deg. sobre Passiflora alata Curtis, em ambiente de nebulização intermitente. Revista Brasileira de Fruticultura, Jaboticabal, v.27, n.1, p.98, 2005.

STAVELEY, G.W.; WOLSTENHOLME, B.N. Effects of water stress on growth and flowering of Passiflora edulis Sims grafted to P. caerulea L. Acta Horticulturae, Wageningen, n. 275, p. 551558, 1990 .

STENZEL. N.M.C.; CARVALHO, S.L.C. Comportamento do maracujazeiro-amarelo (Passiflora edulis Sims f. flavicarpa Deg.) enxertado sobre diferentes porta-enxertos. Revista Brasileira de Fruticultura, Jaboticabal, v.14, n.3, p. 183-186, 1992. 